\title{
La posición de América Latina en el contexto de la globalización
}

\author{
Carlos Bernal Pulido*
}

\section{Planteamiento del problema}

La globalización está transformando nuestra manera de concebir las relaciones entre el individuo y lo público. A lo largo del siglo XX, estas relaciones se articulaban con base en un modelo Keynesiano-Westfaliano. Este modelo partía de la suposición de que el Estado nacional era la institucionalización idónea de lo público. Las relaciones entre el individuo y lo público se identificaban con las relaciones entre el ciudadano y su Estado, aquel Estado que, mediante su ordenamiento jurídico, ejercía un dominio sobre el territorio nacional.

El elemento definitorio de este modelo Keynesiano-Westfaliano es el principio de territorialidad del Estado. ${ }^{1}$ De acuerdo con este principio, las discusiones sobre la justicia deben llevarse a cabo siempre dentro del marco estatal. En América Latina, estas discusiones han girado predominantemente en torno a dos aspectos: la redistribución y el reconocimiento. En el aspecto distributivo, las discusiones sobre la justicia se han referido a qué libertades —en el Estado liberal de derecho- y qué derechos a disponer de medios materiales —en el Estado social de derecho- debe tener cada ciudadano para que el modelo de sociedad pueda considerarse justo. Por su parte, en el aspecto del reconocimiento, minorías rezagadas en la asignación de libertades o derechos a disponer de medios materiales han denunciado la existencia de jerarquías institucionalizadas que, desde un punto de vista cultural, les han negado por entero o de forma desigual el reconoci-

Profesor de Derecho Constitucional e Introducción al Derecho de la Universidad Externado de Colombia.

1 Cfr., sobre este principio, BALDWIN, T. «The Territorial State». En H. Gross y T. R. Harrison (eds.). Jurisprudence, Cambridge Essays. Oxford: Clarendon Press, 1992, p. 207 y ss. 
miento idóneo para una participación, en pie de igualdad, de la interacción económica, política y social. Las reivindicaciones de las minorías étnicas y las de igualdad de género son manifestaciones de la dimensión que han adquirido las discusiones acerca de la justicia. De todas estas discusiones, la opinión pública nacional ha sido por tradición el árbitro supremo.

Debe señalarse que, incluso los movimientos guerrilleros y terroristas, que han pretendido la desestabilización y el vuelco de los sistemas políticos latinoamericanos o el cambio de gobierno, han enderezado sus operaciones en el marco del Estado. Las pretensiones, legales e ilegales, legítimas e ilegítimas, de transformación de lo público se han enfocado hacia la metamorfosis del Estado. Sin embargo, hasta los últimos años, ellas nunca pusieron en jaque el marco estatal ni propusieron su transformación por uno de mayor alcance.

El marco estatal ha sido asimismo la sede nacional para la estructuración de las relaciones de representación política. Dentro del Estado es que se ha pretendido configurar el ideal rousseauniano de construcción de la voluntad general, que, en teoría, permitiría que el sujeto continuara gozando de autonomía, a pesar de la naturaleza heterónoma del derecho. ${ }^{2}$ La representación política dentro del Estado habría de posibilitar que el ciudadano que elige a sus representantes mediante el voto se convirtiera en autor indirecto de las normas jurídicas que él mismo, ulteriormente, habría de obedecer. Esta ecuación no solo habría de organizar la democracia masificada, sino que, además, habría de legitimar la obediencia al derecho por parte de todos sus destinatarios. El derecho se consideraría, de esta manera, como la formalización de la justicia construida por la vía democrática. Del mismo modo, por efecto de esta ecuación, las votaciones se han convertido en la expresión más palpable de la democracia y la regla de la mayoría, en su más depurada esencia. Esta regla no solo ha dictaminado el nombre y el estandarte de los representantes del pueblo en el Congreso y en el Gobierno, sino que, asimismo, ha sido el mecanismo apropiado para zanjar todas las disputas sobre justicia social, distribución de beneficios y cargas y disfrute de derechos.

En todo caso, el modelo Keynesiano-Westfaliano ha presupuesto la igualdad en la participación y en la representación política dentro del Estado de todos los sujetos relevantes políticamente. Como bien se sabe, en un principio, la categorización de los sujetos relevantes políticamente no fue universal. La institucionalización de las primeras democracias en América Latina, tras la independencia de España, se fundamentó en un concepto restringido de ciudadano. Al igual que en la Europa ilustrada, esta categoría estuvo

Cfr. RousSEAU, J. J. El contrato social. Madrid: Taurus, 1969, p. 25 y ss. 
reservada, en un inicio, a los varones propietarios. Las mujeres no eran dignas de la cosa pública, tal como argumentó deplorablemente Rousseau en el Emilio, al paso que la propiedad era la legitimación para intervenir en la deliberación ciudadana. Junto con ello, y de manera análoga en ciertos aspectos a lo que acaeció en los Estados Unidos, la segregación racial de esclavos e indígenas impidió, en un comienzo, la universalidad de la categoría de sujeto políticamente relevante. Con todo, las luchas sociales condujeron a la universalidad de la ciudadanía, es decir, a legitimar la participación en el proceso político en condiciones jurídicas de paridad. Así, el advenimiento del Estado social, a lo largo del siglo XX y a partir de la Constitución de Querétaro de 1917, ha permitido que dichas condiciones de paridad, en algunos aspectos — pues aún falta mucho por andar-, sean también reales.

La globalización, sin embargo, ha puesto en evidencia que, en América Latina y en el mundo entero, las posibilidades que tenga el individuo de vivir una buena vida ya no dependen solo del Estado, sino de procesos que superan sus fronteras territoriales, de procesos supraestatales, internacionales o, incluso, no estatales. ${ }^{3}$ Los latinoamericanos sentimos que muchos de los procesos que afectan nuestras vidas dependen de decisiones que se toman en otros Estados — particularmente en los Estados Unidos_, de la voluntad de empresas transnacionales, de organizaciones supranacionales o internacionales de tipo gubernamental o no y de la opinión pública internacional que fluye a través de la red. Sentimos cada día más que decisiones ajenas a nosotros desencadenan afectaciones para nuestras vidas, sin que, incluso, nuestra Constitución o nuestras instituciones políticas puedan hacer nada. Por ello, ipara muchos filósofos políticos y actores sociales, el Estado ya no puede ser considerado como la institucionalización idónea de lo público, es decir, como el ente adecuado para decidir aquello que sea justo, para determinar cómo ha de hacerse la distribución de derechos y cargas y el reconocimiento de estatus. La filosofía política y el derecho constitucional miran cada día más hacia la globalización, al paso que ya no solo las empresas, sino también los sindicatos, los movimientos sociales, las minorías étnicas y religiosas, los activistas de derechos humanos y los ecologistas buscan una expansión cosmopolita.

La globalización hace necesario cuestionar la legitimidad del marco estatal. En la actualidad, es imprescindible preguntarse cuál debe ser el marco apropiado dentro de la globalización que, al dejar atrás el modelo Keynesiano-

En la reconstrucción de esta crítica al modelo Keynesiano-Wesfaliano, sigo a FRASER, N. "Re-framing Justice in a Globalizing World». En Law and Justice in a Global Society. Anales de la Cátedra Francisco Suárez, 2005, p. 85 y ss. 
Westfaliano, permita a América Latina una participación política en condiciones de igualdad para tratar los problemas de justicia distributiva y de reconocimiento. Y, más aún, es indispensable plantearse la interrogante de cómo debe construirse dicho marco y qué reglas de participación política deben observarse para que dicha construcción ofrezca a América Latina una participación política en condiciones de igualdad.

El objetivo de esta ponencia, que constituye un resultado parcial de investigación, es tratar tres aspectos que tienen que ver con el déficit de igualdad en la representación política que América Latina sufre tras la puesta en marcha de la globalización con base en el modelo Keynesiano-Westfaliano. Dichos aspectos son el déficit de representación política de América Latina en la construcción del marco de la globalización; el déficit de representación política de América Latina y el disfrute inequitativo de libertades y derechos sociales; y, por último, el déficit de representación política que se origina por la emigración.

Estos tres aspectos generan un déficit de representación política de América Latina en la globalización, porque impiden la participación de los ciudadanos del subcontinente en condiciones de igualdad en la toma de decisiones de alcance global. De esta manera, por lo menos en cuanto se refiere a América Latina, se afecta la legitimidad de las decisiones que se adoptan con este déficit. Como sostiene Habermas, basado en el principio del derecho de Kant, la legitimidad del derecho y de toda decisión política se basa en última instancia en un mecanismo comunicativo: como participantes en discursos racionales los miembros de una comunidad jurídica han de poder examinar si la norma o la decisión de que se trate encuentra o puede encontrar el asentimiento de todos los posibles afectados. ${ }^{4}$ Desde este punto de vista, los tres factores que a continuación abordaremos impiden que los ciudadanos de América Latina, a pesar de resultar afectados por ciertas decisiones y normas propias de la globalización, demos o podamos dar nuestro asentimiento a ellas. Tras su estudio, y para concluir, se sugerirán algunas vías de posible solución.

\section{El déficit de representación política de América Latina en la construcción del marco de la globalización}

El déficit más notable de igualdad de representación política de América Latina es el que concierne a su participación en la construcción de un

HABERMAS, J. Facticidad y Validez. Sobre el derecho y el Estado democrático de derecho en términos de teoría del discurso. Madrid: Trotta, 1998, p. 168. 
marco que supere al marco Estatal y que sea apropiado para enfrentar los retos de justicia dentro de la globalización.

Como es bien sabido, la globalización no implica la desaparición del Estado, sino un debilitamiento de su poder hacia el interior y el exterior para permitir el fortalecimiento de los intercambios y las comunicaciones transnacionales. La globalización es un «conjunto multidimensional de procesos sociales que crea, multiplica, despliega e intensifica intercambios e interdependencias sociales en el nivel mundial, a la vez que crea en las personas una conciencia creciente de conexión cada vez mayor entre lo local y lo distante». ${ }^{5}$ La globalización presupone el desmantelamiento de las barreras de protección económica de los Estados ${ }^{6}$ para permitir el libre tránsito de capitales y mercancías y la interdependencia mundial. Asimismo, lleva aparejada la imposición a cada Estado de una política de no intervención en la economía, que se concreta en medidas consistentes, por ejemplo, en abstenerse de subsidiar la producción de ciertas mercancías o de imponer barreras arancelarias a productos provenientes del exterior, a fin de permitir así la libre competencia.

Esta pérdida del poder regulador del Estado lleva consigo su transferencia a otras instancias internacionales — como el Banco Mundial, el Fondo Monetario Internacional y la Organización Mundial del Comercio- y a las empresas transnacionales, así como su capitulación frente a los efectos de las leyes del mercado. En estas circunstancias, los ciudadanos de cualquier país tendrán una participación política efectiva en la toma de decisiones concernientes a la globalización en la medida en que sus representantes puedan participar en las deliberaciones que tienen lugar en el seno de estos organismos. Mientras, como ocurre con América Latina, nuestros representantes no tengan voz propia e influyente en condiciones de equidad en estos organismos, nosotros solo seremos destinatarios del derecho de la globalización, pero no autores, aunque sea indirectos, de sus regulaciones. Sufriremos un déficit de representación política que repercutirá en el desconocimiento de nuestros intereses, que resultarán afectados en todo caso por las decisiones que estos órganos adopten.

En este aspecto, el esquema de relaciones entre el individuo y lo público sufre una aguda distorsión no solo en lo que concierne al ejercicio de las libertades y a la satisfacción de las necesidades básicas, sino también al ejercicio de los derechos democráticos mediante la representación política. Ya no puede seguir afirmándose que la satisfacción de estas libertades y

STENGER, M. Globalization: A Very Short Introduction. Oxford: Oxford University Press, 2003, p. 13

6 Stiglitz, J. E. El malestar en la globalización. Madrid: Taurus, 2002, p. 34. 
necesidades y de dichos derechos constituye el fundamento y el fin del Estado, como quiera que ella comienza a depender de la política económica que hoy día, sobre todo en el mundo subdesarrollado, está hecha a la medida de las directrices del Banco Mundial y el Fondo Monetario Internacional y de los intereses de las empresas transnacionales. Y, a su vez, no puede seguir sosteniéndose que uno de los pilares de la relación entre el individuo y la comunidad política es la participación de aquel en las reglas que gobiernan a esta última, dado que las directrices de estos organismos internacionales de política económica —el gobierno de la globalización - están trazadas por técnicos provenientes de los países industrializados y vinculados a los intereses de las empresas más poderosas. ${ }^{7}$ La globalización ha implicado la pérdida, en un grado elevado, del control que tiene el Estado sobre su propia economía. La economía de cualquier Estado puede verse afectada por desestabilizaciones repentinas, ocasionadas por la huida de capitales o por decisiones adoptadas por parte de las transnacionales, ${ }^{8}$ sin que los órganos de gobierno interno puedan adoptar medidas enteramente eficaces para paliar los efectos negativos de una crisis.

En este nuevo panorama, entonces, el Estado latinoamericano deja de ser de facto el principal referente de la comunidad política, aquel que con su acción fundamentada en el ejercicio democrático puede garantizar al individuo un mínimo vital y proporcionarle los medios indispensables para el ejercicio de su libertad. Su posición como destinatario de los derechos fundamentales prestacionales y de participación política se vuelve enteramente formal; se asemeja a la de un convidado de piedra que permanece inmóvil

Cfr., sobre esta crítica, Ib., p. 44: "Las instituciones [el FMI y el Banco mundial] están dominadas no sólo por los países industrializados más ricos sino también por los intereses comerciales y financieros de esos países, lo que naturalmente se refleja en las políticas de dichas entidades. La elección de sus presidentes simboliza esos problemas y con demasiada asiduidad ha contribuido a su disfunción. Aunque casi todas las actividades del FMI y el Banco Mundial tiene hoy en el mundo subdesarrollado (y ciertamente todos sus préstamos), estos organismos siempre están presididos por representantes de los países industrializados (por costumbre o acuerdo tácito el presidente del FMI es siempre europeo, y el del Banco Mundial siempre es norteamericano). Éstos son elegidos a puerta cerrada y jamás se ha considerado un requisito que el presidente posea alguna experiencia sobre el mundo en desarrollo. Las instituciones no son representativas de las naciones a las que sirven [...]. Los problemas también derivan de quien habla en nombre del país. En el FMI son los ministros de hacienda y los gobernadores de los bancos centrales. En la OMC son los ministros de Comercio. Cada uno de estos ministros se alinea estrechamente con grupos particulares en sus propios países. Los ministros de comercio reflejan las inquietudes de la comunidad empresarial, tanto los exportadores que desean nuevos mercados abiertos para sus productos como los productores de bienes que compiten con las importaciones».

8 Cfr. HeLD, D. La democracia y el orden global. Del Estado moderno al gobierno cosmopolita. Barcelona: Paidos, 1997, p. 162 y ss. 
ante los efectos que las políticas globales proyectan sobre su población. Los deberes de acción que le imponen los derechos fundamentales terminan cediendo ante los deberes de abstención que le impone la globalización. ${ }^{9}$ Como ha subrayado Oswaldo de Rivero en su trepidante libro El mito del desarrollo, el Estado, aquel antiguo leviatán, poderoso y soberano, temible pero inexorable, «se ha autodegradado» para convertirse en un «vicario del capitalismo global $»^{10}$. Y este declive del Estado no ha sido compensado con la creación de un sistema democrático transnacional, gobernado por un "derecho democrático cosmopolita» como el propuesto por David Held. ${ }^{11}$ Aún no se ha fundado un sistema en el que se aumente la simetría entre quienes toman las decisiones y quienes se ven afectados por ellas y en el que las empresas transnacionales que imponen las reglas del mercado sean responsables ante los ciudadanos de todo el mundo, que son precisamente los destinatarios de sus decisiones.

Lo cierto es que la participación política de América Latina en la configuración del marco de la globalización es aún muy precaria. Y ello no solo obedece al déficit de representación política en los órganos de control, sino a la carencia de empresas transnacionales fuertes y al empobrecimiento que ha sufrido por la globalización.

Ya es un lugar común la sentencia que condena a las políticas que han gobernado la economía mundial durante las últimas décadas por haber hecho a los ricos cada vez más ricos y a los pobres cada vez más pobres. Como denuncia Stiglitz, las cifras son escalofriantes: «En la última década del siglo XX el número de pobres ha aumentado en casi cien millones. Esto ha sucedido al mismo tiempo que la renta mundial total aumentaba en promedio un 2.5 por ciento anual». ${ }^{12}$ La política cínica de pretender ayudar a países como los de América Latina, ordenando la apertura de sus mercados, mientras los países industrializados protegían los suyos; ${ }^{13}$ la concentración de la tecnología y de la mano de obra calificada en Estados Unidos, Europa y Japón; la depreciación de las materias primas y de las manufacturas no industriales; la vigencia de férreas leyes de propiedad intelectual confeccionadas en

Cfr. Habermas, J. "La constelación posnacional y el futuro de la democracia». En La constelación posnacional. Ensayos políticos. Barcelona: Paidos, 2000, p. 104 y ss.

10 RIVERO, O. de. El mito del desarrollo. Los países inviables en el siglo XXI. 2. ${ }^{\text {a ed. Lima: }}$ Fondo de Cultura Económica, p. 53.

11 Held, D. Op. cit., p. 44. Asimismo, véase Id. "Principles of Consmopolitanism Order». En Law and Justice in a Global Society. Anales de la Cátedra Francisco Suárez, 2005, p. 145 y ss.

12 StIGlitz, Joseph E. Op. cit., p. 30.

$13 \quad$ Ib., pp. 17 y 31. 
la Ronda de Uruguay a la medida de los productores y no de los consumidores; y la depredación de la ecología han polarizado al mundo en una especie de apartheid económico global en el que se distingue, por un lado, una aristocracia de dominadores, interconectados en red, que se juegan la suerte del planeta en los centros financieros y que gobiernan el mundo haciendo lobbie ante los gobiernos más poderosos y los organismos multilaterales; y, por otro, un contingente cada vez más numeroso de excluidos, desempleados o trabajadores en condiciones precarias, que deambulan en los cinturones de miseria de las urbes del mundo subdesarrollado o intentan emigrar en condiciones poco dignas. Desde esta perspectiva, la globalización es contradictoria: incluye a todas las regiones y grupos humanos del planeta en el juego del capitalismo y, al mismo tiempo, excluye a ciertas regiones y grupos de sus beneficios. A su vez, el círculo se cierra y se vuelve perpetuo, pues los países que no pueden participar de los beneficios de la globalización tampoco pueden, por ello, participar en la confección del marco globalizado. Como consecuencia, las reglas globalizadas no tomarán en cuenta sus intereses y necesidades y, por ello, los excluirán de nuevo de sus beneficios.

\section{El déficit de representación política de América Latina y el disfrute inequitativo de libertades y derechos sociales}

En estas condiciones, los hasta ahora llamados países en desarrollo, la mayoría de los latinoamericanos entre ellos, devienen víctimas de una suerte de darwinismo económico internacional que parece convertirlos más bien en países inviables. ${ }^{14}$ En los países inviables, la fundamentación del Estado en la necesidad de proteger los derechos fundamentales del individuo, sobre todo las libertades y los derechos sociales, adquiere un tinte quimérico - piénsese tan solo en el derecho al trabajo y el derecho a alimentarsecuando no el de un ardid retórico para justificar la nuda explotación.

Tiene razón José María Rosales cuando afirma que, en este esquema del Estado nacional, es decir, en el modelo Keynesiano-Westfaliano, "la ciudadanía define el modo de pertenencia de los individuos a la comunidad política» y, al mismo tiempo, ${ }^{15}$ se convierte en la clave de acceso a los derechos de libertad, a los derechos de participación en la actividad del Estado

RIVERO, O. de. Op. cit., pp. 97 y ss.

15 ROSAlES, J. M. Patriotismo, nacionalismo y ciudadanía: en defensa de un cosmopolitismo cívico. Serie de Teoría Jurídica y Filosofía del Derecho, n. ${ }^{\circ}$ 4. Bogotá: Universidad Externado de Colombia, 1997, pp. 21 y 41. 
y a los derechos de bienestar económico y social. ${ }^{16}$ Solo el ciudadano es quien disfruta con toda plenitud de los derechos fundamentales liberales, democráticos y prestacionales. ${ }^{17}$ Como quiera que la protección de los derechos implica un alto costo, esta no puede extenderse a todos los individuos. La ciudadanía es el criterio -internamente inclusivo y externamente exclusivo- ${ }^{18}$ mediante el cual se delimita el grupo de titulares de los derechos de cuyo goce el Estado es responsable directo.

En el modelo Keynesiano-Westfaliano, el Estado es responsable de garantizar al individuo el ejercicio de su libertad y sus derechos sociales y democráticos. Como bien se sabe, este es precisamente el mayor de los fundamentos y las finalidades del Estado en los más conocidos escritos de filosofía política. La idea central consiste en que el individuo está investido de ciertas facultades básicas que le son inherentes y que no puede ejercer si el Estado no las protege mediante su actuación. Esta idea ha justificado la existencia del Estado desde la óptica de las teorías liberal, democrática y del Estado social.

De acuerdo con la tesis liberal, la finalidad del Estado es proteger el ejercicio de la libertad y los bienes personalísimos del individuo. Locke, por ejemplo, sostuvo que la legitimidad del poder del Estado descansa sobre la base de la protección de la "vida, libertad y hacienda" del individuo o, en sus propias palabras, que "el fin supremo y principal de los hombres al unirse en repúblicas y someterse a un gobierno es la preservación de sus propiedades». ${ }^{19}$ Por su parte, Kant señaló que la principal directriz de la acción del Estado es el conocido "principio general del Derecho», según el cual, «una acción es conforme a derecho cuando, según ella, la libertad de arbitrio de cada uno puede conciliarse con la libertad de todos, según una ley general». ${ }^{20}$ Este principio muestra claramente cómo Kant atribuye al Estado, y en particular a la legislación, la labor fundamental de proteger y armonizar la libertad de todos los individuos.

Para Rawls, en un sentido similar, la persona está caracterizada por dos facultades morales que constituyen el núcleo de sus atributos como sujeto

$16 \quad$ Ib., p. 43.

17 Cfr., sobre el concepto y las diferencias entre estas clases de derechos, BERNAL PULIDO, C. "Capítulo III». En El principio de proporcionalidad y los derechos fundamentales. 2. ed. Madrid: Centro de Estudios Políticos y Constitucionales, 2005.

18 Cfr., sobre esta característica de la ciudadanía, BRUBAKER, R. "Capítulo I». En Citizenship and Nationhood in France and Germany. Cambridge (Mass.): Harvard University Press, 1992.

19 LOCKE, J. Dos ensayos sobre el gobierno civil. Madrid: Espasa Calpe, 1991, p. 293.

20 KANT, I. Introducción a la teoría del derecho. Madrid: Centro de Estudios Constitucionales, 1978, p. 80 . 
libre y cuya protección está atribuida al Estado. La primera facultad moral consiste en la aptitud de tener un sentido de la justicia — capacidad de ser «razonable», en la terminología de este autor- ${ }^{21}$ Por su parte, la segunda facultad se define como la «capacidad para albergar una concepción del bien» — capacidad de ser «racional»—. ${ }^{22}$ La primera facultad moral se identifica con la disposición humana para tomar parte de manera consciente en la cooperación social y para respetar los términos en que esta se desenvuelve. La segunda facultad moral, en cambio, se refiere a la capacidad de proponerse objetivos y de «perseguir una concepción de lo que consideramos que en la vida vale la pena». ${ }^{23}$ Entre las dos facultades existe una relación manifiesta: mientras la primera alude a los presupuestos individuales de la asociación política, la segunda recalca las posibilidades que esta asociación reconoce al individuo.

Estas dos facultades morales sirven de criterio para determinar la lista de libertades básicas del individuo que deben ser protegidas por toda comunidad política justa. De las facultades morales de la persona se deriva el inventario de libertades que han de ser tenidas en cuenta por los fundadores del Estado y que luego han de materializarse en el catálogo de derechos fundamentales. ${ }^{24}$ De acuerdo con Rawls, de este catálogo solo pueden formar parte las libertades que sean «esenciales» para el desarrollo de las capacidades de la persona, es decir, las libertades de pensamiento y de conciencia, las libertades políticas de asociación, las libertades físicas y de integridad de la persona y los derechos y libertades implícitas en el principio de legalidad. ${ }^{25}$

En segundo lugar, la teoría democrática también ha esbozado una concepción del sujeto, compuesta por un conjunto de atributos o facultades básicas, cuya protección representa el fundamento y la finalidad del Estado. La clave de esta concepción se encuentra en el concepto de autonomía y aparece ya expuesta in nuce en el ideal de Rousseau de «encontrar una forma de asociación que defienda y proteja de toda fuerza común a la persona y a los bienes de cada asociado, y por la cual cada uno, uniéndose a todos, no se obedezca sin embargo más que a sí mismo, y permanezca así libre». ${ }^{26}$ La teoría democrática propugna la atribución al individuo de la mayor

\footnotetext{
${ }^{21}$ RAwLS, J. El liberalismo político. Trad. de A. Doménech. Barcelona: Grijalbo - Mondadori, 1996, p. 49 y 338.

22 Ib., p. 338.

23 Ib., loc. cit.

24 Ib., p. 330.

25 Ib., p. 328.

26 ROUSSEAU, J. J. Op. cit., p. 25
} 
capacidad posible para darse normas a sí mismo; defiende un entendimiento del hombre como sujeto soberano, capaz de autogobernarse, que tiene el derecho de no obedecer más que a sus propios designios.

Esta idea central de la teoría democrática ha conocido, en las últimas décadas, un vigoroso auge en la teoría del discurso pergeñada por J. Habermas y algunos de sus discípulos. El concepto de persona democrática o de persona deliberante es el más relevante de los desarrollos de la teoría del discurso si la observamos desde el punto de vista de los derechos fundamentales. Así como Rawls ha esbozado un concepto liberal de persona, los defensores de la teoría del discurso han expuesto las características antropológicas que su concepción presupone. Como es bien sabido, en la teoría de Habermas, la clave de funcionamiento del Estado y del derecho se halla en el llamado principio del discurso. De acuerdo con este principio, solo deben ser consideradas normas válidas aquellas a las que todos los afectados puedan prestar su asentimiento en calidad de participantes en discursos racionales. ${ }^{27}$ De esta equivalencia entre el principio del discurso y el principio democrático se deriva que el concepto de persona presupuesto por el principio democrático se identifica con el concepto de persona que exige el principio del discurso o, en otros términos, que la persona democrática es la persona deliberante en un discurso racional.

El principio del discurso presupone una persona capaz de deliberar y de prestar su asentimiento. Esta circunstancia permite explicar por qué, desde el punto de vista de la teoría del discurso, el concepto de persona se articula básicamente en torno a la capacidad de discernimiento de cada individuo ("Zurechnungsfähigkeit»). Esta capacidad se define como la habilidad indispensable que cada hablante debe poseer para tomar parte en la comunicación. ${ }^{28}$ La capacidad de discernimiento engloba dos facultades susceptibles de ser predicadas de la persona: por una parte, la capacidad para hacer afirmaciones y para defenderlas de la crítica con razones convincentes y, por otra, la capacidad de ser crítico con las afirmaciones de los demás y con las suyas propias, es decir, las aptitudes de crítica y autocrítica, a la última de las cuales se suma, además, la facultad de autocorrección. ${ }^{29}$

HABERMAS, J. Facticidad y validez. Sobre el derecho y el Estado democrático de derecho en términos de teoría del discurso. Op. cit, p. 172.

28 HABERMAS, I. Teoría de la acción comunicativa. T. "l: "Crítica de la razón funcionalista». Madrid: Taurus, 1987, p. 110.

29 GÜNTHER, K. «Welchen Personenbegriff braucht die Diskurstheorie des Rechts? Überlegungen zum internen Zusammenhang zwischen deliberativer Person, Staatsbürger und Rechtsperson». En H. Brunkhorst y P. Niesen (eds.). Das Recht der Republik. Fráncfort del Meno, 1999, p. 83 y ss. 
Estas facultades son el objeto principal de protección de los derechos fundamentales y, en conjunto, como concepto democrático de persona, son el presupuesto del estatus de ciudadano. Por esta razón, desde el punto de vista de la teoría democrática, los derechos fundamentales prioritarios son los derechos políticos y la dimensión participativa de otros derechos liberales y prestacionales como la libertad de expresión e información o el derecho a la educación.

Por último, también la teoría del Estado social perfila una imagen del sujeto que debe ser protegido por el Estado y que se compone esta vez no de un conjunto de facultades sino de necesidades básicas. Según esta línea de pensamiento, ninguna concepción sobre el contenido de los derechos fundamentales, en cuanto fundamento del Estado, puede desconocer que "grandes sectores de la comunidad no pueden valerse por sí mismos». ${ }^{30}$ De acuerdo con Tugendhat, uno de sus principales valedores en el ámbito filosófico, el sistema de derechos fundamentales no puede sostenerse sobre la presunción errada de que la sociedad está conformada enteramente por individuos capaces, autónomos y autosuficientes, que además intervienen en condiciones de igualdad en la toma de decisiones políticas. Por esta razón, su base no puede estribar en el concepto de libertad sino en el de necesidad o, con mayor precisión, de necesidades inherentes al hombre.

La idea de necesidades inherentes al hombre no es por entero incompatible con el liberalismo. Detrás de las nociones de libertad negativa y de autonomía, que fundamentan la concreción de los derechos fundamentales en deberes de abstención, subyace también el reconocimiento de que el individuo tiene la necesidad de elegir y de decidir su propio rumbo. No obstante, la idea de necesidad se extiende sobre otros planos soslayados por el pensamiento liberal. Esta idea también pone de relieve que la situación de carencia de los bienes indispensables para subsistir y para ejercer las libertades en que se encuentran vastos sectores de la población de los Estados es un hecho de relevancia social. De esto se sigue que el imperativo de satisfacer las necesidades básicas de toda la población fundamente ciertas reglas de cooperación que también integran el contenido de los derechos fundamentales. Estas reglas de cooperación desarrollan el principio de solidaridad ${ }^{31}$ conforman los derechos fundamentales prestacionales y prescriben

TUGENDHAT, E. Lecciones de ética. Barcelona: Gedisa, 1997, p. 338 y ss.

$31 \quad M$. Borgetto ha señalado que el principio de solidaridad cumple la función de fundamentar en alguna medida ciertos derechos sociales. En esta dimensión, la solidaridad se entiende como un "deber colectivo de ayuda mutua», como un "verdadero principio de acción política». En BORGETTO, M. La notion de Fraternité en Droit Public Français. París: LGDJ, 1993, p. 398. 
deberes de actuar que tienen un doble efecto de irradiación. ${ }^{32}$ Dichos deberes se proyectan, en primer lugar, sobre el propio afectado - a quien su estatus inicial como persona autónoma le impone una obligación de autoayuda - y sobre sus familiares y allegados, quienes tienen con el afectado un vínculo de solidaridad muy estrecho. Sin embargo, si estas obligaciones positivas no pueden ser satisfechas en esta primera instancia, se traspasan, de modo subsidiario, a todos y cada uno de los miembros de la sociedad que se aúnan en el Estado para procurar el correspondiente deber prestacional. ${ }^{33} \mathrm{La}$ ejecución de estos deberes prestacionales debe proveer el mínimo vital a todos los individuos y los bienes necesarios para el ejercicio de su libertad y sus derechos políticos.

Tras todo lo anterior, es pertinente reconocer que estos tres bastiones de la fundamentación de la comunidad política: libertades, derechos democráticos y necesidades, están construidos solo a la medida del marco estatal. Su estructuración no reconoce que, en el mundo globalizado, no todos los Estados están en las mismas circunstancias y que no todos pueden garantizar a sus ciudadanos las mismas libertades, derechos sociales y derechos democráticos en condiciones de igualdad. Es evidente que la ciudadanía se convierte en un factor de discriminación en el disfrute de estas ventajas entre los países dominantes y dominados de la globalización. En primer lugar, la globalización garantiza un máximo de libertades económicas y no económicas a los ciudadanos de los países dominantes, que en ocasiones es incompatible con las libertades de las que disfrutan los ciudadanos de los países que no participan en el gobierno global. La libertad de locomoción, de circulación personal, de establecimiento y de intercambio no está garantizada de la misma forma para personas naturales y jurídicas provenientes de estos dos ámbitos. Los ciudadanos de los Estados fuertes reciben mayor protección y garantía, fronteras libres y subvenciones para la expansión, y, de este modo, avorazan en la competencia mundial a los ciudadanos de estados más débiles.

En segundo lugar, la ciudadanía supone un límite al deber de solidaridad, que es el fundamento y la garantía de los derechos sociales. El Estado de bienestar está construido dentro de las fronteras estatales y se basa en

TUGENDHAT, E. Op. cit., p. 341 y sS.

33 Del mismo modo, J. J. Gomes Canotilho ha hecho ver que el imperativo que se desprende de los derechos sociales vincula a todos los miembros de la sociedad y se hace efectivo sobre todo por los contribuyentes, quienes proporcionan al Estado los recursos necesarios para atender las prestaciones correspondientes. Véase GOMES CANOtILHO, J. J. "Metodología "Fuzzy" y "Camaleones normativos" en la problemática actual de los derechos económicos, sociales y culturales». Derechos y Libertades, n. ${ }^{\circ}$ 6, 1998, p. 39 y ss. 
una obligación especial de dar ayuda prioritaria a los compatriotas. Esta intuición de particularidad, ampliamente aceptada, contradice, sin embargo, como ha mostrado recientemente Takikawa, la idea de universalidad apoyada por la moral kantiana y por el utilitarismo. Según esta idea, debemos tratar a los demás de igual forma, sin dar prioridad a nadie, sean cuales sean su raza, sexo, creencias religiosas o nacionalidad. ${ }^{34}$ El estado de bienestar establece una barrera entre los que están adentro y los que están fuera de él. Solo asiste a los necesitados nacionales. De este modo, los estados de bienestar que tienen capacidad económica para solidarizarse con los necesitados se enfocan en sus propios ciudadanos y excluyen a los que no lo son. Por el contrario, muchos de los Estados de América Latina, si no todos, carecen de la capacidad económica real para atender las necesidades básicas ligadas a los derechos sociales de sus propios ciudadanos. Si esta circunstancia se combina con la intuición de particularidad en virtud de la cual estos ciudadanos no recibirán tampoco atención de otros Estados con mayor capacidad económica, se llegará entonces a la conclusión de que los derechos sociales de estos ciudadanos permanecerán siempre como una promesa incumplida de sus Constituciones y de los documentos internacionales que los contienen.

Por último, y como ya se mencionó en el aparte anterior, los ciudadanos de nuestros Estados tienen también individualmente un déficit de representación política en la globalización. La ecuación rousseaniana se rompe en nuestros Estados, pues nuestra voluntad no interviene en igualdad de condiciones en la construcción de la ley globalizada, es decir, en la conformación de la voluntad global. Mientras tanto, en el ámbito nacional, en el que en teoría aún alguna influencia debería tener, nuestra voluntad pierde terreno por la influencia del ámbito global. No solo no somos ciudadanos en el ámbito global, sino que somos menos ciudadanos en nuestro propio Estado, cuyas decisiones democráticas cada vez significan menos en su propio territorio. A nadie escapa la percepción de que la voluntad general del Estado depende cada vez menos de las decisiones de sus congresos y gobiernos y responde cada vez más a las imposiciones globales. El Estado no solo deja de actuar, sino que incluso actúa de conformidad con los dictados del capitalismo global.

TAKIKAWA, H. "Can We justify the Welfare State in an Age of Globalization? Toward complex Borders». En Law and Justice in a Global Society. Anales de la Cátedra Francisco Suárez, 2005, p. 723 y ss. 


\section{Emigración y déficit de representación política}

Otro de los esquemas básicos del modelo Keynesiano-Westfaliano es la visión clásica de la soberanía estatal, en la que se considera que la mejor manera de proteger los derechos humanos, la más legítima y eficaz, es mediante su institucionalización como derechos fundamentales oponibles por cada ciudadano a su propio Estado. Se entiende que se llega a la mejor forma de garantizar el respeto de los bienes y capacidades básicas del individuo, junto con la paz y la armonía internacional, cuando el Estado ejerce su soberanía sobre sus ciudadanos y cuando se respeta el principio de independencia de los Estados y de no intervención entre ellos. ${ }^{35}$

Debe reconocerse que este esquema ciertamente se basa en un argumento en principio plausible: el fundamento democrático de los derechos humanos. ${ }^{36} \mathrm{Si}$ el ámbito estatal es aquel en donde por excelencia se ejerce la democracia, es entonces en el marco del Estado en donde deben protegerse los derechos humanos y no en el contexto internacional ni en el dominio de otros Estados. La protección en el ámbito internacional debe reducirse a los casos en que el propio Estado sea quien vulnere los derechos y cuando su protección no se haya conseguido mediante los procedimientos internos. A este argumento se suma la idea de que la forma y el grado de cumplimiento de los derechos humanos debe depender siempre de las circunstancias fácticas y sociales. Estas circunstancias varían en uno y otro lado del planeta y el ámbito estatal constituiría un marco apropiado para determinarlas y para decidir cuál es la manera más pertinente para proteger los derechos humanos de acuerdo con ellas. ${ }^{37}$

La pregunta es, no obstante, si este esquema de protección de los derechos humanos mediante su institucionalización como derechos fundamentales del ciudadano puede funcionar adecuadamente en un mundo como el actual, en que los límites entre las sociedades se han diseminado como consecuencia de la globalización y de los actuales procesos migratorios, ${ }^{38}$

35 Cfr. KOlleR, P. «Die Internationalisierung der Menschenrechte und die Grenzen staatlicher Souveranität». En H. Brunkhorst, W. R. Köhler y M. Lutz-Bachmann. Recht auf Menschenrechte. Menschenrechte, Demokratie und internationale Politik. Fráncfort: Suhrkamp, 1999, p. 231.

36 Cfr., sobre este argumento, MICHELMAN, F. I. «Brauchen Menschenrechte eine demokratische Legitimation?». En H. Brunkhorst, W. R. Köhler y M. Lutz-Bachmann. Op. cit., p. 52 y ss. También, en el mismo volumen, véase HABERMAS, J. «Der interkulturelle Diskurs über Menschenrechte», p. 216.

37 Cfr. MiChelman, F. I. Op. cit., p. 62.

38 También en este sentido parece argumentar KOLLER, P. "Der Geltungsbereich der Menschenrechte». En S. Gosepath y G. Lohmann. Philosophie der Menschenrechte. Fráncfort: Suhrkamp, 1999, pp. 101-102. 
que en gran medida son también producto de la pobreza que estos procesos económicos a escala mundial han engendrado. En otros términos, se trata de saber si, en estas condiciones actuales, el esquema de relaciones entre el individuo y la comunidad política basado en el concepto de ciudadanía, aunado con las restricciones para migrar a otros Estados diferentes del propio y para adquirir en ellos el estatus de ciudadano, consigue ser un esquema apropiado para proteger las facultades básicas de la persona, finalidad última de toda comunidad política.

Debido a la pobreza y a las guerras, según cifras del año 2000, más de 100 millones de personas viven fuera de su país de origen y, de este número, 20 millones son refugiados. ${ }^{39}$ Bien puede pensarse que estas cifras representan solo un pequeño porcentaje de la población mundial. Sin embargo, aun en estas proporciones, la migración desafía tanto a los países de origen como a los de acogida. En los primeros, significa la devastación de múltiples estructuras familiares, culturales, económicas y sociales; la fuga de mano de obra y de ingenio; el escape de cerebros; y la correlativa disolución de las esperanzas de desarrollo y progreso. Los países de emigrantes, como muchos de América Latina, se hacen dependientes de las remesas provenientes del extranjero, que, en la mayoría de los casos, se invierten en bienes de consumo y, por ello, se alejan aún más de la creación de infraestructura y de redes tecnológicas e industriales que hagan competitivas a sus economías. En los países de acogida, la inmigración varía el panorama económico y cultural y exige redefinir la estructura de la demanda de trabajo y los valores de la comunidad. El migrante, por su parte, padece una situación de exclusión en los dos estadios. Emigra porque se considera excluido de las posibilidades de progreso en su lugar de origen y puede experimentar también la exclusión del mercado y la sociedad a la que se desplaza.

Por su parte, la política para contrarrestar la inmigración que se desarrolla en el seno de la globalización parece estar marcada por un sino de contradicciones. ${ }^{40}$ Se garantiza el derecho de salir de cualquier país, pero no el de entrada a los países industrializados. La globalización pregona el imperio del liberalismo, pero se trata de un liberalismo amañado, que postula la libre circulación del capital pero no del trabajo. Los países pobres desdeñan la emigración de científicos y trabajadores muy cualificados, estos sí apetecidos por las multinacionales asentadas en el mundo desarrollado, al paso que los trabajadores no cualificados son repudiados por los primeros, que

39 Cfr. CASTLES, Stephen. "Globalization and Migration: some pressing Contradictions». En Ethnicity and Globalization. Londres - Thousand Oaks - New Delhi: Sage Publications, 2000, p. 125.

40 Cfr., sobre algunas de estas contradicciones, ib., p. 125 y ss. 
los consideran una carga social, y rechazados también por los países industrializados. Las restricciones a la entrada de inmigrantes no logran contener el desplazamiento de los menesterosos, sino que abren espacio a un nuevo mercado: el mercado negro de la inmigración; el reino de las organizaciones ilícitas de trata de personas, que hacen del hombre moneda de cambio; y el imperio de la explotación laboral de los inmigrantes, que los convierte en los esclavos de nuestro tiempo.

Asimismo, los emigrantes sufren un déficit de participación política. La distancia les impide participar activamente en la deliberación pública de su propio país, al paso que la carencia de ciudadanía del país de acogida los hace sujetos del derecho sin capacidad absoluta de intervenir en su construcción. Por último, en palabras de Manuel Castels, se crea la tensión entre the net and the self, entre la red y el yo, entre lo global y lo provincial; el mundo industrializado tiende a querer, al mismo tiempo, dominar el planeta entero, extender sus productos y sus tentáculos a los confines de la tierra, y replegarse en sí mismo, proteger con muros sus fronteras y su cultura.

Estas contradicciones de la política migratoria de los países industrializados desconocen que, en una destacable medida, la migración es un producto natural de las políticas económicas globales, que ellos mismos han impulsado, y que, por tanto, es también una consecuencia indirecta de sus propias acciones. Los países receptores de inmigrantes son asimismo responsables en parte de la inmigración..$^{41}$ Las contradicciones de la política de inmigración que los países industrializados imponen al mundo globalizado hacen ineficaz a esta política y ponen de manifiesto la precariedad del modelo de relaciones entre el individuo y la comunidad basado en el sedentarismo y en la protección de las facultades básicas del individuo exclusivamente en forma de derechos fundamentales contra su propio Estado. ¿Acaso las facultades básicas de los inmigrantes o de los ciudadanos de los Estados que gobiernan los países subdesarrollados no son tan dignas de tutela como las de los ciudadanos de los países industrializados? ¿Puede aceptarse que la protección efectiva de estas facultades se rija por un régimen particular que escapa a la globalización y que confina la tutela del individuo a los avatares de cada unidad estatal, sin importar lo que allí ocurra? ¿Sucede entonces que la protección de estas facultades es el fundamento de la comunidad política en la era estatal, pero no en la era global? Lo más sensato parece ser aceptar el estruendoso fracaso del modelo tradicional de protección del individuo en el marco estatal. Pero, si es necesario descartar este

41 Cfr. JOPPKE, Ch. Inmigration and the Natio - State. The United States, Germany, and Great Britain. Oxford: Oxford University Press, 1999, p. 1 y ss. 
modelo, ¿qué alternativas restan? A continuación, exploraremos dos vías de salida: la República mundial y el modelo de los Estados interdependientes.

\section{Hacia un nuevo marco de relación entre el individuo y la comu- nidad política}

\section{La República mundial}

La primera alternativa posible al modelo tradicional es la República mundial. En este modelo, cuyos lineamientos se ajustarían en gran medida a lo esbozado por Kant en su ensayo sobre la paz perpetua, la ciudadanía dejaría de funcionar como un criterio exclusivo hacia el exterior. En otros términos, todos los seres humanos seríamos ciudadanos de un mismo Estado; la ciudadanía sería cosmopolita, absolutamente inclusiva y dejaría de cumplir sus funciones de criterio para discernir entre los seres humanos. Por esta misma razón, existirían sistemas de protección planetaria de las facultades básicas de todos los individuos por igual y cada ciudadano del mundo estaría vinculado jurídicamente por el deber de solidaridad que lo haría en parte responsable de la satisfacción de las necesidades básicas de sus congéneres, sin que pudieran mediar distinciones entre ellos.

Es muy probable que este modelo de República universal sea el más justo de todos los posibles. La ciudadanía cosmopolita sería el sustrato ideal para que el principio de universalidad de los derechos humanos se realizara en su óptima medida. Sin embargo, por lo menos al corto plazo, la implantación súbita de un sistema semejante no parece más que una utopía. Por una parte, cabe reconocer que, en la mayoría de los discursos legitimadores del poder público, el concepto de ciudadanía no tiene solo un carácter jurídico formal, sino que se suele emparentar con elementos culturales relativos a la existencia de una identidad nacional o de entendimientos y valores compartidos. ${ }^{42}$ Independientemente del juicio que se tenga sobre lo correcto de estas posturas, o sea, sobre si algo semejante a una identidad nacional o a un grupo de valores compartidos pueda existir aun en los conglomerados humanos más homogéneos, lo cierto es que los discursos nacionales campean a sus anchas por los cinco continentes y no pueden ser desconocidos por entero. Por otra parte, permitir de golpe la migración irrestricta posiblemente devastaría aún más a los países pobres y causaría desajustes mayúsculos, culturales y económicos, en el mundo desarrollado. Es bien factible que un tránsito inopinado hacia la ciudadanía cosmopolita se

$42 \quad$ Ib., p. 6. 
pagara con más depredación e iniquidad que las hasta ahora existentes. La creación de la República mundial exige un proceso de evolución paulatino y estable, en el que la justicia vaya imponiéndose paso a paso al compás de la edificación de formas renovadas de democracia. La libertad planetaria de locomoción y de trabajo únicamente puede proceder de una deliberación entre los países de salida y de llegada y de estabilización entre ambos tipos de sociedades, en la que se escuche a los ciudadanos de unas y otras. Solo de esta manera se contaría con la opinión y la aceptación de todos los afectados y, poco a poco, se generarían los nexos de solidaridad entre unos y otros, sin los que la República mundial no sería nada distinto de un nuevo artificio para encubrir el estado de naturaleza, el reino de los poderes salvajes.

\section{El modelo de los Estados interdependientes}

La segunda alternativa consiste en establecer un modelo intermedio entre el hasta ahora existente y la República mundial. En este modelo intermedio, se conservaría la independencia de los Estados nacionales, pero se afianzaría su interdependencia en cuanto a la protección de las facultades básicas del individuo y la satisfacción de sus necesidades vitales mediante el fortalecimiento de los nexos de solidaridad entre unos y otros y, sobre todo, mediante la eliminación del déficit de igualdad de representación política en la globalización. Estos objetivos se lograrían fundamentalmente por medio de dos estrategias: la extensión de la democracia y de los principios de justicia social a la globalización y el diseño de las políticas de migración a escala mundial.

Para lo primero, es necesario que se consolide una opinión pública global y que se constituyan organismos de gobierno internacional, con una composición democrática, en la que se discutan las políticas económicas mundiales y se exija una responsabilidad política, social y ecológica a las empresas transnacionales y a los organismos financieros multilaterales -el FMI y el Banco Mundial- El diseño de estas políticas debe dejar de ser una competencia exclusiva de los países industrializados y debe producirse mediante una deliberación en condiciones de equidad entre todos los afectados por ellas. El gobierno de la globalización debe incluir a todos los seres humanos y debe reflejar los intereses y las necesidades de productores y consumidores, de quienes ganan y quienes pierden con los intercambios mercantiles internacionales. Solo así podrá producir un reparto justo de las cargas y los beneficios económicos, ecológicos y humanos.

En lo que concierne al segundo aspecto, los países de acogida de los inmigrantes deben hacerse conscientes de que la política de inmigración no puede seguir considerándose como una manifestación soberana del derecho 
de autodeterminación, que puede ejercerse con una discrecionalidad absoluta e irresponsable. ${ }^{43}$ La política de inmigración es también un asunto que debe regirse por los principios de justicia que rigen el Estado constitucional democrático y debe responder a las exigencias de protección de los derechos humanos. También vulnera los derechos humanos una política que proteja los derechos fundamentales de los ciudadanos y eleve su umbral de satisfacción hasta las cotas más altas y a la vez soslaye los derechos humanos de los inmigrantes y del resto de la humanidad. En este mismo sentido, la política de inmigración debe dejar de depender en exclusiva de las necesidades de la clientela política y debe abandonar el terreno de la retórica electoral que intenta capturar el voto de los ciudadanos que ven en el inmigrante una amenaza contra su cultura y su derecho al trabajo. Más bien, debe aceptarse que la inmigración es una consecuencia natural de la globalización, que implica múltiples oportunidades de crecimiento para los países de acogida y representa una vía para la protección de las facultades básicas de un sinnúmero de individuos que no encuentran en sus propios países las condiciones políticas o económicas para llevar una existencia digna. La actitud frente al inmigrante debe ser de empatía, solidaridad y confianza, en vez de rechazo y menosprecio.

Asimismo, la política de migración debe dejar de ser un asunto interno de los países de acogida. Por el contrario, debe comenzar a ocupar la agenda de la discusión democrática en los encuentros bilaterales entre Estados y, sobre todo, en los foros internacionales y multilaterales. Ante el rotundo fracaso de las políticas represivas, lo idóneo es crear planes internacionales de mejoramiento de las condiciones económicas y sociales en los países pobres y programas de migración legal concertados por todos los afectados.

Por último, tanto en los países de partida como en los de acogida, es indispensable implementar políticas de reajuste económico y cultural para paliar los efectos de la migración. La integración del inmigrante en los países de acogida es uno de los mayores desafíos del milenio que ha comenzado. Las políticas que intentan paliar la discriminación - y las medidas jurídicas $-{ }^{44}$ son, desde luego, la piedra angular de cualquier respuesta a este desafío. Sin embargo, esta también exige entablar un diálogo cultural entre los valores de la sociedad originaria del inmigrante y la sociedad de acogida. La integración necesita que esta última se interese por conocer los valores

\footnotetext{
Ib., pp. 2 y 17.

44 Téngase como ejemplo la línea jurisprudencial norteamericana, que conoció su inicio en la sentencia Plyler frente a Doe, según la cual las diferenciaciones fundadas en la calidad de inmigrante deben ser consideradas como clasificaciones sospechosas y deben ser enjuiciadas mediante el test estricto de la igualdad.
} 
imperantes en las sociedades de donde proceden los inmigrantes e intente encontrar puntos de diálogo y equilibrio con los propios. No hay integración sin simbiosis cultural. ${ }^{45}$ La dictadura de los valores de la sociedad de acogida es únicamente una puerta abierta para la segregación, los guetos, la opresión y el rechazo.

45 Cfr., en este sentido, HABERMAS, J. "Die interkulturelle Diskurs über Menschenrechte». Op. cit., p. 219. 